\title{
Whey proteins and its impact on human health nutrition: review
}

\begin{abstract}
Now a days, researchers showed some interest in whey protein products because of its nutritional value and showed its importance in human health nutrition. Whey protein is one of the two proteins that is reported in milk, other being casein protein. In simple words, when any coagulant e.g. renin is added to milk, the curds (casein) and whey separate. Whey protein is the water-soluble part of milk and used as a protein supplement. In addition, whey protein contains a number of bioactive components including beta-lactoglobulin, alpha- lactalbumin, immunoglobulin, and lactoferrin. Further, whey protein is also one of the great sources of branched chain amino acids, which are particularly useful for athletes and sarcopenic conditions. In this review, we summarize the components of whey protein and the recent findings regarding its importance on human health nutrition.
\end{abstract}

Keywords: whey protein, amino acid, lactoferrin, alpha lactalbumin, beta lactoglobulin, immunoglobulin, lipid, glucose
Volume 3 Issue 7 - 2016

\author{
Amit Gupta, Jaydeep B Jadhav, Kiran D \\ Gunaware, Bharat Shinde \\ 'Department of Immunology and Virology,Vidya Pratishthan's \\ School of Biotechnology (VSBT), Research Centre affiliated to \\ Savitribai Phule Pune University, Baramati, India \\ ${ }^{2}$ Department of Zoology, Arts, Science and Commerce College, \\ Baramati, India
}

\begin{abstract}
Correspondence: Amit Gupta, Department of Immunology and Virology, Vidya Pratishthan?s School of Biotechnology VSBT, Research Centre, Savitribai Phule Pune University, Department of Zoology, Arts, Science and Commerce College, Baramati,
\end{abstract} Maharashtra, India,Tel 830888I506, Email amitgupta@vsbt.res.in

Received: November II, 2016 | Published: December 29, 2016
Abbreviations: WPC, whey protein concentrate; WPI, whey protein isolate; WPH, wey protein hydrolysate; GMP, guanosine monophosphate; Ig, immunoglobulin; IgG, immunoglobulin G; IgM, immunoglobulin $\mathrm{M}$; IgA, immunoglobulin $\mathrm{A} ; \mathrm{H}_{2} \mathrm{O}_{2}$, hydrogen peroxide; GSH, glutathione; GLP-1, glucagon-like peptide 1; GIP, glucose-dependent insulinotropic peptide; DPP-IV, dipeptidyl peptidase-IV

\section{Introduction}

Milk is one of the important sources of nutrition that is widely consumed for human consumption and this can be obtained from a number of domesticated animals (sheep, goat, buffalo and cow) e.g. fresh cow milk containing approximately $3.5 \%$ total protein, out of which $80 \%$ casein, $15 \%$ whey protein, as well as vitamins, and lipids that provides necessary ingredients for growth. ${ }^{1,2}$ In other words, energy (carbohydrate) obtained from milk in the form of lactose (sugar), nitrogen (protein; subcomponents of micro fractions) and rich source of calcium (for bones). ${ }^{3,4}$ Most of the biologically active components (e.g. lactoferrin, lactoperoxidase, lysozyme, and immunoglobulins etc.) that are present in the whey fraction of milk which showed antimicrobial properties. ${ }^{3,4}$ Whey proteins mean that protein which is separated out from the casein and these are purified into different concentrations and are generally useful for wound healing, weight loss, infant health etc. It is one of the excellent proteins for all age groups especially for healthy diet and maintains their health. ${ }^{1,2,5,6}$ Due to variability in carbohydrates, fat, immunoglobulins, lactose and minerals including essential amino acids that are reported in whey protein of milk collected from domesticated animals. ${ }^{7}$ As shown in Figure 1, data represents the variations in whey protein of various domesticated animals and showed that sheep and goat almost similar and higher in whey protein content as compared to bovine (cow) animals. The protein concentration of these whey proteins in milk samples of different animal species (e.g. goat, sheep and bovine) will be determined through Nano Drop method.

Whey proteins are especially used as supplement for food and beverages in various industries. Actually, these proteins are used for medicinal purpose and improve the health status of all age groups of human. One of the most familiar examples is reported in Type 2 diabetes where this protein is generally involved in controlling or maintaining the blood glucose levels and also provides additional benefits including weight management. ${ }^{6-8}$

Whey protein is collected from different domesticated animals and these are purified from whey liquid through removal of a number of constituents due to the processes involved in purification. ${ }^{9}$ Three types of whey protein are reported i.e. whey protein concentrate Figure 1. Variations in whey protein of domesticated animals (WPC; low but still significant level of fat and cholesterol; higher bioactive compounds), whey protein isolate (WPI; remove fat and lactose content but lower in bioactivated compounds) and whey protein hydrolysate (WPH; pre-digested and partially hydrolysed; highly hydrolysed whey may be less allergenic). As per the literature, number of immunological components that are reported in whey protein. ${ }^{5-9}$

\section{Amino acid content}

Amino acid content is one of the most important factor in bovine milk proteins especially caseins and whey proteins that can be regarded as a complete source of amino acids. In contrast, milk proteins will be regarded as main source of immunobiologically active peptides which might have nutritional value. ${ }^{10,11}$ Generally, whey protein contained all the essential amino acids but this amino acid cannot be able to produce itself with in the body. As per the literature, nine essential amino acids are reported and each one of it has own function. So, it is important to get more and more essential amino acids each day for maintaining lean muscle mass. ${ }^{10,11}$ In general, whey contained number of amino acid residues including branched chain amino acids e.g. leucine, isoleucine and valine. These branched chain amino acids comprised up to onethird of muscle protein and also involved in protein synthesis and various metabolic processes as well. In addition, only these amino acids are not degraded in the liver but other amino acids are normally regulated by gut and liver. Consuming these branched chain amino acids before training can increase uptake into the muscle tissue and showed many benefits e.g. increase growth hormone circulation; 
lower lactate levels and improve muscular oxidation; decrease serum concentrations of intramuscular enzymes creatine kinase and lactate dehydrogenase etc. All these factors are responsible in branched amino acids which showed less muscle damage and improved some recovery. ${ }^{12,13}$ In other words, branched amino acids are continuously released from the liver and other internal organs to skeletal muscle so that these branched amino acids can assist in maintaining blood sugar levels. Indeed, branched amino acids may be responsible and showed up to $40 \%$ (approximately) of blood sugar production during exercise. $^{12,13}$

As per the literature, sulphur containing amino acids i.e. cysteine and methionine are found in high concentrations in whey protein, contributing to enhanced immune function through intracellular conversion to glutathione. ${ }^{14}$ Interestingly, one of the nucleotides i.e. Guanosine monophosphate (GMP), also known as 5'-guanidylic acid or guanylic acid GMP which supplemented in bovine milk in order to increase the concentration to a level that is similar to the concentration found in human milk. Although a source of branched amino acids lacked these aromatic amino acids i.e. phenylalanine, tryptophan and tyrosine that may be responsible to reduce the burden of various diseases especially hepatic encephalopathy. ${ }^{12-14}$

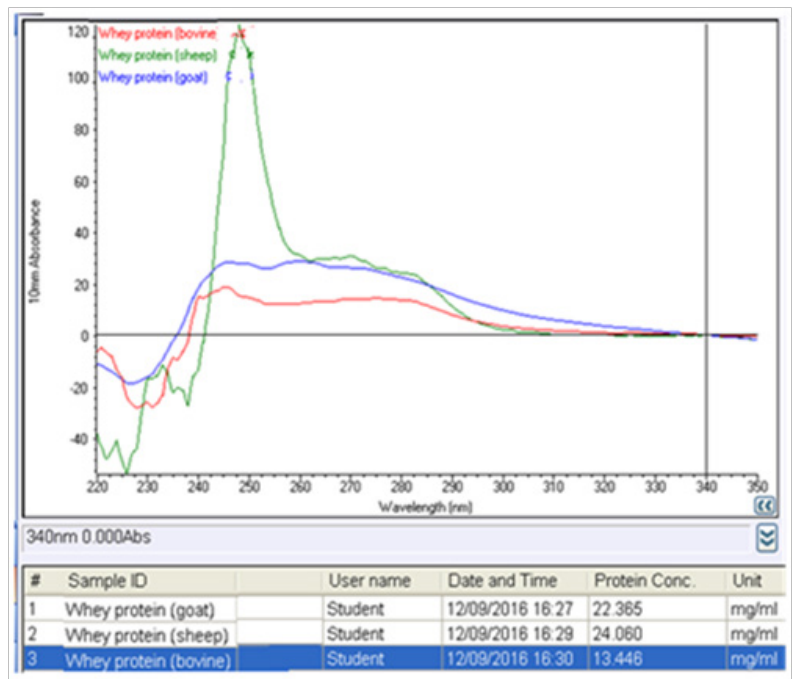

Figure I The variations in whey protein of various domesticated animals.
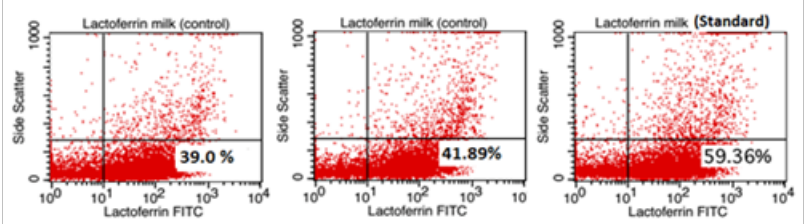

Figure 2 Flow cytometric estimation of Lactoferrin content in bovine milk samples.

\section{Lactoferrin}

Lactoferrin (iron binding glycoprotein) consists of approximately 689 amino acid residues and its concentration in human milk $(2 \mathrm{mg} /$ $\mathrm{ml})$ and colostrums $(7 \mathrm{mg} / \mathrm{ml})$ respectively; while in bovine milk $(0.2 \mathrm{mg} / \mathrm{ml})$ and colostrums $(1.5 \mathrm{mg} / \mathrm{ml})$ respectively. ${ }^{15,16}$ According to the literature, lactoferrin is reported as anti-microbial and antiinflammatory agent and also have the capability to induce the activity of natural killer cells and colony stimulating factor including the activation of macrophages. ${ }^{15,16}$ As shown in Figure 2, variation in bovine milk count especially lactoferrin content ranging from 22.39 to $36.56 \%$ (10,000 cells gated; BD FACS Calibur; cell quest software) whereas lactoferrin capsule used as standard and the value ranges from 39 to $41.89 \%$ (10,000 cells gated). In human, lactoferrin is one of the most significant content or diet for children through breast milk for less than two years of age. Now a day, bovine lactoferrin including recombinant human lactoferrin are available commercially and is normally added to various food products including milk which is beneficial for our immune system and showed antibacterial and antiviral activities in the intestine against various pathogens. In addition, it may regulate the iron content of infants and also in pregnant women via receptor-mediated pathway.

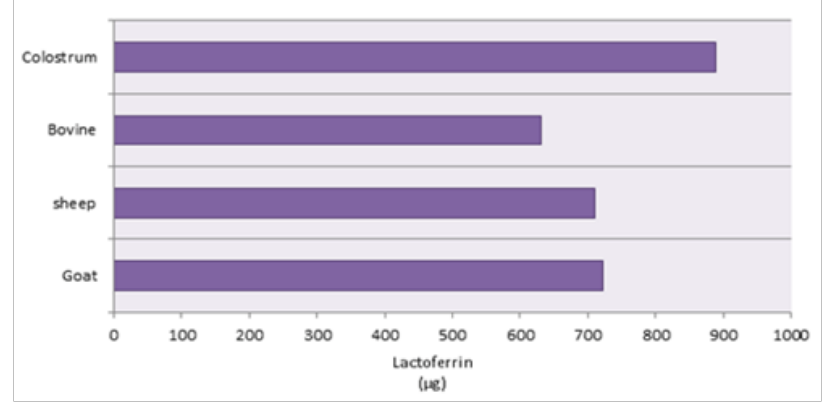

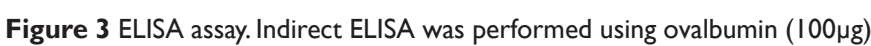
as coating antigen. Milk samples from different animals were used for the estimation of lactoferrin antibody titre. Horse anti-serum used as secondary antibody and optical density measured at $450 \mathrm{~nm}$.

$$
\begin{aligned}
& \text { Cysteine (contained antioxidant thiol group) + Glycine + Glutamate } \\
& \downarrow \\
& \text { (Major endogenous antioxidant produced by cells) } \\
& \downarrow \\
& \text { Protect RNA, DNA and proteins via redox cycling from GSH (reduced form) to GSSH (oxidized form) }
\end{aligned}
$$

Figure 4 Synthesis and its action of glutathione.

Note: Direct conjugation, GSH detoxifies a host of both endogenous and exogenous toxins including toxic metals, petroleum distillates, lipid peroxides, bilirubin and prostaglandins.

\section{Immunoglobulins}

Number of studies that are already claimed that several components especially immunoglobulins (blood group proteins) exists in whey protein that are responsible for enhancing its immunity. The highest concentration of these immunoglobulins is still reported in colostrum (first milk after birth). As per the literature, Immunoglobulins exists in the form of antibodies (i.e. IgG, IgM, IgA, and Secretory IgA; Ig stands for Immunoglobulin) in whey protein that are beneficial for the treatment of various bacterial infections. ${ }^{17}$ In other words, these immunoglobulins provide passive maternal immunity to infants through breast milk and helped to maintain our immune system. Overall, immunoglobulins showed significant $10-15 \%$ of total whey proteins derived from bovine milk. Out of these immunoglobulins, IgG has been found at concentrations of $0.6-0.9 \mathrm{mg} / \mathrm{ml}$ in bovine milk. Other studies also showed that raw milk from non-immunized cows contains specific antibodies against $E$. coli, Salmonella enteriditis, $S$. typhimurium, Shigella flexerniand human rotavirus. ${ }^{17}$ In one of the studies related to lactoferrin content in milk samples of different animal species i.e. cow, sheep and bovine as shown in Figure 3. The results showed that colostrum produced much higher lactoferrin content followed by goat, sheep and bovine. ${ }^{15,16}$

\section{Lactoperoxidase}

It is one of the most abundant enzyme which is reported in bovine milk and showed anti-bacterial properties against various pathogens. 
Generally, this enzyme has been used in combination with hydrogen peroxide $\left(\mathrm{H}_{2} \mathrm{O}_{2}\right)$ and thiocyanate $\left(\mathrm{SCN}^{-}\right)$worked as antimicrobial agent in raw milk samples where pasteurization is not feasible. ${ }^{18-20}$ In contrast, this enzyme has the ability to inhibit hydrogen peroxide $\left(\mathrm{H}_{2} \mathrm{O}_{2}\right)$, catalysing peroxidation of thiocyanate and certain halides (including iodine and bromium). Whey's antioxidant and detoxifying activity is most likely linked to its contribution to the synthesis of glutathione (GSH) and its action ${ }^{18-20}$ as shown in Figure 4.

\section{Lactalbumin}

One of the major milk serum proteins i.e. alpha-lactalbumin which showed antiproliferative effects in human cell lines especially in case of adenocarcinoma such as Caco-2 and HT29. In contrast, alpha-lactalbumin reported three polypeptide fragments and showed antimicrobial activity against $E$. coli, Klebsiella pneumoniae, Staphylococcus aureus, Staphylococcus epidermis, Streptococci, and C. albicans. As per the literature, content of alpha-lactalbumin is much higher in cow's milk and observed cases of allergic response in many individuals. ${ }^{21,22}$ It is one of the most serious problem for young children who are often able to use or consumed goat milk without suffering that reaction i.e. allergy. The percentage of alpha lactalbumin varies from animal to animal e.g. cow (52.9-53.6\%); sheep (8.97-17\%); goat (13.31-34.7\%) and human $(30.3-45.4 \%))^{21-23}$

\section{Lactoglobulin}

Beta-lactoglobulin is another major whey protein which affects milk composition or its components and functionality of product including binding hydrophobic ligands such as fatty acids. According to the literature, human milk is totally free from $\beta$-lactoglobulin and it is reported in whey protein of sheep's, goat's and mare's milk. ${ }^{24}$ The percentage of beta lactoglobulin is reported in cow (18.4-20.1\%), sheep (59.24 -77.7\%) and goat (43.54-63.8\%). In this protein, it contained anti-hypertensive peptides that are responsible for decline in blood pressure and also showed significant effect on angiotensin converting enzyme inhibitors. Most of the beneficial effect related to peptides formation through the hydrolysis of whey proteins. These whey peptides is one of the major peptides that are responsible for inhibiting angiotensin converting enzyme, which induces bloodpressure regulating effects. ${ }^{24}$

\section{Effects on lipid and glucose metabolism}

Numerous studies were conducted and demonstrated the effect of whey protein on glucose and lipid metabolism. As per the literature, long term intake of whey protein (maximum 12weeks) that showed significant decrease in fasting plasma concentrations of triacylglycerols in overweight and obese individuals. ${ }^{25}$ Actually, the mechanism of whey protein related to triglycerols is not clear mentioned. Afterwards, scientists conducted number of immunological studies and claimed that meal containing whey protein showed drastic declined in production of chylomicrons and accelerated chylomicron clearance resulting from the stimulation of lipoprotein lipase. In addition, whey protein intake inhibits blood glucose and insulin levels, including decrease in fasting plasma insulin levels (11\%) after 12 weeks of whey protein intake $\left(54 \mathrm{~g} /\right.$ day) in adults. ${ }^{26}$ In contrast, whey protein also showed some effect on lipid metabolism as well and showed decrease in postprandial triglycerides including free fatty acids and the rate of appearance of chylomicron-rich lipoproteins after a high-fat meal in type 2 diabetes patients. ${ }^{26,27}$

Immunological studies were performed in rats and claimed that supplementation or intake of whey protein possibly decline in serum glucose level. This could be possible only due to inhibition of enzyme (dipeptidyl peptidase-IV; DPP-IV) and its function is to disable the incretin hormones (i.e. glucagon-like peptide 1, GLP-1 and glucosedependent insulinotropic peptide, GIP) both of them related to glycemic control. ${ }^{26-28}$ Similarly in mice model studies, digestion of whey protein leads to the formation of di- and tri-peptides that are a substrate for DPP-IV. In healthy individuals, increased in the amount of GLP-1 levels due to consumption of whey protein is more acceptable. Recently, Veldhorst et al. observed an increase in blood insulin (approx.91\%) and GLP-1 (approx.. 164\%) levels after consumption of diet containing $25 \%$ calories of protein (whey protein), $55 \%$ carbohydrates and $20 \%$ lipids as compared to similar quantities of casein in order to reduce serum glucose and insulin levels. In addition, there is non-significant reduction of blood glucose content with the consumption of whey when compared to casein was observed. In short, major benefit from whey protein has resulted in a number of human and animal studies which is designed to elucidate the active component of whey and their mechanisms of action. In rats, whey protein supplements inhibits liver lipid content but only when lipids were increased with a high-cholesterol diet. ${ }^{26-29}$ In short, no severe adverse reactions were reported in human with the administration of these whey products. Finally, these whey protein products are likely to be safer for humans. High doses of these whey protein products can cause side effects i.e. increased bowel movements, nausea, thirst, cramps, reduced appetite, fatigue, and headache. Reports indicate that whey may be beneficial for weight control; however, owing to its rapid absorption, it can also readily be stored as fat.

\section{Conclusion}

Milk is one of the oldest functional foods available to mammals. Number of preclinical and clinical studies was conducted by various scientists related to whey protein products for human health nutrition. Although the combined results of preclinical and clinical trial data provide clear evidence regarding its use, whey protein is likely to show some beneficial changes to the metabolic status of healthy and diseased patients. Further studies investigating the mechanisms underlying the effects of whey protein are needed.

\section{Acknowledgments}

None.

\section{Conflicts of interest}

Author declares there are no conflicts of interest.

\section{Funding}

None.

\section{References}

1. Foegeding EA, Davis JP, Doucet D, et al. Advances in modifying and understanding whey protein functionality. Trends in Food Science \& Technology. 2002;13(5):151-159.

2. Marshall K. Therapeutic applications of whey protein. Alt Med Rev. 2004;9(2):136-156.

3. Lollo PC, Farfan AJ, de Carvalho-Silva LB. Physiological and physical effects of different milk protein supplements in elite soccer players. $J$ Hum Kinet. 2011;30:49-57.

4. Josse AR, Phillips SM. Impact of milk consumption and resistance training on body composition of female athletes. Med Sport Sci. 2012;59:94-103. 
5. Athira S, Mann B, Sharma R, et al. Ameliorative potential of whey protein hydrolysate against paracetamol-induced oxidative stress. $J$ Dairy Sci. 2013;96(3):1431-1437.

6. $\mathrm{Xu} \mathrm{R}$, Liu $\mathrm{N}, \mathrm{Xu} \mathrm{X}$, et al. Antioxidative effects of whey protein on peroxide induced cytotoxicity. J Dairy Sci. 2011;94(8):3739-3746.

7. Blome RM, Drackley JK, McKeith FK, et al. Growth, nutrient utilization, and body composition of dairy calves fed milk replacers containing different amounts of protein. J Anim Sci . 2003;81(6):1641-1655.

8. Mortensen LS, Hartvigsen ML, Brader LJ, et al. Differential effects of protein quality on postprandial lipemia in response to a fat-rich meal in type 2 diabetes: comparison of whey, casein, gluten and cod protein. Am J Clin Nutr. 2009;90(1):41-48.

9. Saito T. Antihypertensive peptides derived from bovine casein and whey proteins. Adv Exp Med Biol. 2008;606:295-317.

10. Coker RH, Miller S, Schutzler S, et al. Whey protein and essential amino acids promote the reduction of adipose tissue and increased muscle protein synthesis during caloric restriction-induced weight loss in elderly, obese individuals. Nutr J. 2012;11:105.

11. Burd NA, West DW, Moore DR, et al. Enhanced amino acid sensitivity of myofibrillar protein synthesis persists for up to $24 \mathrm{~h}$ after resistance exercise in young men. $J$ Nutr. 2011;141(4):568-573.

12. De Bandt JP, Cynober L. Therapeutic use of branched-chain amino acids in burn, trauma, and sepsis. $J$ Nutr. 2006;136(30):8S-13S.

13. Luigi F, Nicole EC, Apelo A, et al. Decreased Consumption of Branched-Chain Amino Acids Improves Metabolic Health. Cell Rep. 2016;16(2):520-530.

14. Grimble RF, Grimble GK. Immunonutrition: role of sulfur amino acids, related amino acids, and polyamines. Nutrition. 1998;14(7-8):605-610.

15. Gupta A, Chaphalkar SR. Quantitative estimation of lactoferrin and leukocytes contents in bovine, sheep and goat samples. J Adv Food Sci Tech. 2016;3(1):21-24.

16. Gupta A, Chaphalkar SR. Flow cytometric estimation of lactoferrin content in bovine milk samples. J Adv Food Sci Tech. 2016;3(1):36-40.

17. Bell SJ. Whey protein concentrates with and without immunoglobulins: a review. J Med Food. 2000;3(1):1-13.

18. Steele WF, Morrisons M. Antistreptococcal activity of lactoperoxidase. J Bacteriol. 1969;97(2):635-639.
19. Björck L, Rosen CG, Marshall V, et al. Antibacterial activity of lactoperoxidase system in milk against pseudomonas and other gram negative bacteria. Appl Microbiol. 1975;30(2):199-204.

20. Shin K, Hayasawa H, Lönnerdal B. Purification and quantification of lactoperoxidase in human milk with use of immunoadsorbents with antibodies against recombinant human lactoperoxidase. Am J Clin Nutr. 2001;73(5):984-989.

21. Kelleher SL, Chatterton D, Nielsen K, et al. Glycomacropeptide and alpha-lactalbumin supplementation of infant formula affects growth and nutritional status in infant rhesus monkeys. Am J Clin Nutr. 2003;77(5):126-128.

22. Ren J. Alpha-lactalbumin possesses a distinct zinc binding site. J Biol Chem. 1993;268(26):19292-19298.

23. Potoctnik K, Gantner V, Kuterovac K, et al. Mare's milk: composition and protein fraction in comparison with different milk species. Mljekarstvo. 2011;61(2):107-113.

24. Le Maux S, Giblin L, Croguennec T, et al. $\beta$-Lactoglobulin as a molecular carrier of linoleate: characterization and effects on intestina epithelial cells in vitro. J Agric Food Chem. 2012;60(37):9476-9483.

25. Gunnarsson PT, Winzell MS, Deacon CF, et al. Glucose-induced incretin hormone release and inactivation are differently modulated by oral fat and protein in mice. Endocrinology. 2006;147(7):3173-3180.

26. Takasaki K, Nakajima T, Ueno K, et al. Effects of combination treatment with dipeptidyl peptidase IV inhibitor and sulfonylurea on glucose levels in rats. J Pharmacol Sci. 2004;95(2):291-293.

27. Frid AH, Nilsson M, Holst JJ, et al. Effect of whey on blood glucose and insulin responses to composite breakfast and lunch meals in type 2 diabetic subjects. Am J Clin Nutr. 2005;82(1):69-75.

28. Mannucci E, Pala L, Ciani S, et al. Hyperglycaemia increases dipeptidyl peptidase IV activity in diabetes mellitus. Diabetologia. 2005;48(6):1168-1172.

29. Nagaoka S, Kanamaru Y, Kuzuya Y. Effects of whey-protein and casein on the plasma and liver lipids in rats. Agric Biol Chem. 1991;55(3):813-818. 